\title{
Estimation of Actual Evapotranspiration using Remote Sensing data
}

\author{
$\underline{\text { N. Gamage }}^{1,2}$, V. Smakhtin ${ }^{2}$ and B.J.C. Perera ${ }^{3}$ \\ ${ }^{1}$ School of Engineering and Science, Victoria University, PO Box 14428, Melbourne, Victoria, Australia Email: \\ nilantha.gamage@live.vu.edu.au
}

${ }^{2}$ International Water Management Institute, PO Box 2075, Colombo, Sri Lanka.

${ }^{3}$ Faculty of Health, Engineering and Science, Victoria University, PO Box 14428, Melbourne, Victoria, Australia.

\begin{abstract}
Estimation of actual evapotranspiration (AET) and its spatial distribution are important to understanding of catchment hydrology. The AET is driven by net energy available to evaporate water from soil and vegetation surfaces, and to transpirate water from vegetation. However, estimating AET is difficult as the evapotranspiration process involves complex physical and biological processes. It is further complicated when there is lack of measured meteorological variables data which are required for estimation. These data are essential to quantify the availability of net energy and the aerodynamic effects of the evapotranspiration process. Remote sensing (RS) data, which are widely available and easily accessible than the measured ground data, can be used to estimate the availability of net energy for AET. However, still some measured ground data are required to quantify the aerodynamic effects on AET. In this study, remote sensing data and readily available climate datasets were used as inputs to an energy balance technique to estimate AET, as an alternative to the traditional ET estimation procedures, which require measured hydrometeorological data. The Macalister subcatchment in the Thomson catchment in Victoria (Australia) was used as the case study considering the study period from January 2003 to December 2008.
\end{abstract}

Reflectance and radiance data of Moderate Resolution Imaging Spectroradiometer (MODIS) on Terra satellite were the primary source of RS data. Tilted and absent images of Terra MODIS were replaced with Aqua satellite data. First, vegetation indices such as Normalized Difference Vegetation Index, Leaf Area Index, fractional vegetation coverage and broadband albedo were calculated based on MODIS reflectance data for non-cloudy days. Similarly, MODIS radiance data were used to generate daily surface temperature on non-cloudy days. Vegetation indices and surface temperature were then used in the Surface Energy Balance System (SEBS) to estimate AET for non-cloudy days. However, SEBS requires data on a limited number of meteorological variables to quantify the aerodynamic effect of AET, and those data were obtained from ground measurements and global climate datasets (i.e. IWMI climate and water atlas). Once the AET was estimated for non-cloudy days, Geostationary Operational Environmental Satellite (GOES) data were used to calculate fractional cloud cover and used to estimate net radiation available for cloudy day AET. The accuracy of the non-cloudy and cloudy day AET estimated using RS data was studied using root mean square error (RMSE) and Nash-Sutcliffe efficiency $\left(E_{f}\right)$, by considering Penman-Monteith (PM) based AET as the observed AET, at four different sites in the catchment. A crop coefficient was used to convert PM based reference crop evapotranspiration to PM based AET. Remote sensing based AET shows higher coefficient of determination $\left(\mathrm{R}^{2}\right)$ compared to PM based AET on non-cloudy days and comparatively less $\mathrm{R}^{2}$ on cloudy days. Results revealed that RS based AET overestimated during non-cloudy days, especially when the AET is more than $3 \mathrm{~mm} /$ day. However, RS based AET underestimated during partial and total cloud days. The above observations are common to all selected sites. Similar observations were seen with RMSE and $E_{f}$ at all sites. The results show that remote sensing data and global climate dataset can be successfully used to estimate AET for the catchments where required ground measured meteorological data are not available. The estimated AET can be used as input to streamflow simulation models to generate streamflow in data poor catchments.

Keywords: Actual evapotranspiration, Remote Sensing, Surface Energy Balance System 


\section{INTRODUCTION}

Approximately, 62 percent of precipitation which falls on land surfaces evapotranspirates, and the evapotranspiration exceeds runoff in a majority of the hydrological catchments on the earth's surface (Dingman, 1994). Evapotranspiration (ET) is a combined process where water evaporates from open water sources (such as water bodies, vegetation surfaces and soil surfaces) and transpirates through vegetation stomata (Chow et al., 1988). Availability of energy and water, and the ability to transport water vapour through the atmosphere affect the rate of evaporation, while the availability of energy, vapor pressure deficit and the amount of soil moisture control the transpiration rate (Biggs et al., 2008; Bastiaanssen et al., 1998; Su, 2002). The quantity of water per unit time that evapotranspirates from a reference crop surface which has sufficient water is called reference crop evapotranspiration (Allen et al., 1998). In most situations, water availability is limited due to lack of precipitation and deep percolation, and ET occurring under those conditions is referred to as actual evapotranspiration (AET).

ET is second to precipitation in magnitude with respect to annual terrestrial water balance (Chow et al., 1988). Therefore, understanding of ET and its quantification are essential for policy makers, managers, scientists and hydrologists responsible for water management and water allocation decisions, hydrological modeling, irrigation scheduling and weather forecasting. Additionally the knowledge of ET will assist in understanding the long term landuse landcover changes as well as the climate change effect on ET (Glenn et al., 2007). ET can be quantified in two different ways: direct measurements and estimation with meteorological variables. Lysimeters are used to measure ET directly and have been used mostly in agricultural areas. They produce accurate measurements. However, with the absence of lysimeters, in past studies ET has been estimated using water balance or energy balance formulae (Thornthwaite, 1948; Penman, 1948; Monteith, 1965; Priestley and Taylor, 1972). These formulae use various meteorological variables to estimate PET, and then PET is multiplied by a crop coefficient $\left(k_{c}\right)$, which is unique to a particular crop and stage of growth, to obtain AET.

Data for these meteorological variables, which are essential for PET estimation, are not collected for most catchments. In some cases meteorological data have been collected, but the accessibility to these collected data is limited or denied, and therefore not available for PET estimation and hydrological studies. In addition to unavailability and/or non-accessibility of the required meteorological data, heterogeneity of the surface vegetation makes the ET estimation difficult. This estimation is even more difficult, when the vegetation does not cover the whole area of interest. Traditional PET estimation formulae such as Penman-Monteith (PM) and Priestley-Taylor (PT) (Allen et al., 1998; Priestley and Taylor, 1972) have been successfully used for small homogenous study areas, assuming the area is adequately represented by a particular meteorological station. These procedures cannot be successfully used for large areas, due to the lack of representative meteorological stations ( $\mathrm{Su}, 2002)$.

Remote sensing (RS) has numerous advantages for estimation of hydrometeorological variables including ET over large areas (Kite and Pietroniro, 1996), as remote sensing data provide a better representation of surface heterogeneity compared to point estimates obtained from local meteorological station data. RS data have better accessibility than the traditional meteorological data, and are available at no cost from data providers via internet. With such advantages, Su (2002) suggested that surface energy balance formulae could be used to estimate AET using remote sensing data as inputs, and developed Surface Energy Balance System (SEBS) to estimate AET. In this method, leaf area index, surface temperature and surface albedo, which are all estimated from RS data were used as inputs to surface energy balance formulae with few meteorological variables such as air temperature, wind speed, daily average ground radiation (sunshine hours) and vapour pressure deficit obtained from ground measurements. However, ground measured data on these meteorological variables, especially wind speed, daily average ground radiation and vapour pressure are not available for many areas in the world. Therefore, it is necessary to obtain data for these variables through alternative sources such as the freely available global meteorological databases of IWMI climate and water atlas and the University of East Anglia climate dataset, where these data are readily available in various spatio-temporal scales over country, region and global levels (New et al., 2002). Generally these databases are high quality products with a higher spatial resolution but often with a lower temporal resolution. The IWMI climate and water atlas was developed based on the collected meteorological data on a global scale. It has been widely used for regional and global scale applications, but has yet to explore the applicability for water catchments. The study described in this paper focuses on estimating AET using remote sensing data and other publicly available data products (such as IWMI climate and water atlas). The ultimate aim of this project is to use these AET values to generate streamflow using remote sensing data for catchments where meteorological data are not available. The surface energy balance system $(\mathrm{Su}, 2002)$ was used in this study to estimate daily AET, as it has a self-calibration mechanism which can be used to avoid the tedious manual calibration. 


\section{STUDY AREA AND DATA}

The Macalister subcatchment of the Thomson catchment in Victoria (Australia) shown in Figure 1.was selected as the study area. The Macalister subcatchment (hereafter referred to as the catchment) is located $250 \mathrm{~km}$ east of Melbourne and covers an area of 2,250 $\mathrm{km}^{2}$. The catchment originates from Mt. Howitt in the Alpine National Park snowy mountains. The upper area of the catchment is hilly and the elevation is over 1,000 m above Australian Height Datum (AHD). The elevation is approximately 1,000 m (AHD) in the middle area of the catchment and approximately $250 \mathrm{~m}$ (AHD) in the lower part. The middle and lower parts consist of plain areas, which are mostly used for grazing and animal husbandry. These land utilizations are common in near proximities along the river. Rainfall is the major source of precipitation in the catchment area, however patches of snow can be seen in higher mountains (above $1,400 \mathrm{~m}$ ) especially in winter, but melt quickly. The mean annual precipitation reduced in magnitude from North to South, and approximately 2,500 $\mathrm{mm}$ in the upper areas, 1,000 $\mathrm{mm}$ in the middle areas and $600 \mathrm{~mm}$ in the lower areas. Landcover of the upper catchment is dominated by undisturbed forest with Mountain Ash, Alpine Ash, Snow Gum and other mixed species (Peel et al., 2000). The annual evapotranspiration varies with altitude as well as with landuse landcover. The upper catchment area rated nearly $950 \mathrm{~mm}$ of actual evapotranspiration annually (www.longpaddock.qld.gov).

Relevant data were collected for the period from 2003 to 2008. This period was selected because of the availability of data with Moderate Resolution Imaging Spectroradiometer (MODIS). MODIS and Geostationary Operational Environmental Satellite (GOES) data were used as remote sensing data in this study, while daily air temperature and wind speed were used as meteorological data. Required daily reflectance and radiance data were obtained from MODIS. Daily air temperature data were collected from the Bureau of Meteorology (www.bom.gov.au) for the meteorological stations shown in Figure 1. These daily air temperature data were used with Shuttle Radar Topography Mission (SRTM) digital elevation model to obtain air temperature values over the entire catchment (in raster format), considering the elevation differences. Required wind speed data were acquired from the IWMI climate and water atlas

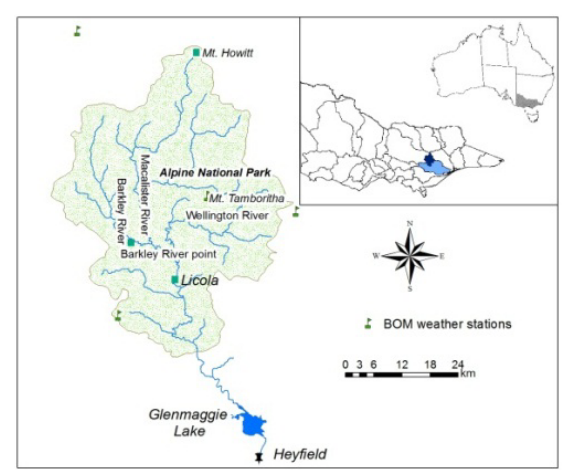

Figure 1 Study area showing meteorological stations.

(http://dw.iwmi.org/atlas/CD1.zip). Calibration of this data has been done using a large number of meteorological stations, and the low Mean Absolute Difference (MAD) obtained through calibration has shown that the product produces the wind speed well over the Australian continent (New et al. 2002). The required Penman-Monteith ET data (from interpolated Data Drill) were collected from the SILO dataset (www.longpaddock.qld.gov) and these data are widely used to calculate AET as a surrogate for ET measurements in the Australia (Fitzmaurice and Beswick, 2005).

MODIS is the main sensor of both Terra and Aqua satellites which cross the equator at morning and afternoon respectively. MODIS was especially selected as it is an advanced sensor to its predecessor Advance Very High Resolution Radiometer (AVHRR). MODIS provides better sensitivity to vegetation and other ground features with its specific sensor characteristics (Thenkabail et al., 2004). MODIS sensor acquires data on a daily basis in 36 spectral bands, with variable spatial resolution of 250-1,000 $\mathrm{m}$ (depending on band). These MODIS bands are designed for atmospheric, land and ocean studies, while the first seven bands are considered optimal for land applications (Justice et al., 2002). MODIS data which are on the Terra platform were collected from Level 1 and the Atmospheric Archive and Distribution System (LAADS) web portal of NASA (http://ladsweb.nascom.nasa.gov/data/search.html). Terra MODIS data were used as the primary source of RS data, because of higher quality scans as a result of morning overpasses having less aerosol effect and appropriate sun angle. Tilted and absent images of the Terra were replaced with the Aqua images. GOES data (https://wist.echo.nasa.gov) which are available on every $30 \mathrm{~min}$ intervals were used to estimate cloud cover (sunlight hours) in this study to estimate AET.

\section{METHODOLOGY}

\subsection{Estimation of Actual Evapotranspiration}

The AET estimation process consists of two components: the estimation of net energy balance and the estimation of 
aerodynamic effect. The net energy balance is used to estimate available energy, and is done through SEBS in this study. The aerodynamic effect calculates sensible heat flux, and then latent heat flux, which is used to calculate the instantaneous evaporative fraction $(\Lambda)$ (Bastiaanssen et al., 1998; $\mathrm{Su}, 2002$ ). The instantaneous evaporative fraction is defined as the ratio of the actual evaporative demand to the crop evaporative demand (which occurs when the atmospheric moisture conditions are in equilibrium with the soil moisture conditions). This instantaneous evaporative fraction value is considered as the average daily evaporative fraction, because the evaporative fraction tends to be constant during daytime hours and the difference between the instantaneous evaporative fraction computed during a satellite overpass and the evaporative fraction derived from a 24-hour integrated energy balance is often marginal (Bastiaanssen et al., 1998).Thus, the daily actual evapotranspiration $E T_{24}(\mathrm{~mm} /$ day) can be estimated as ( $\mathrm{Su}, 2002)$ :

$$
E T_{24}=\frac{86400 \times 10^{3}}{\lambda \times \rho_{\mathrm{w}}} \Lambda \times R_{\mathrm{n} 24}
$$

where $R_{\mathrm{n} 24}$ is the daily averaged net radiation $\left(\mathrm{W} / \mathrm{m}^{2}\right), \lambda$ is the latent heat of vaporization $(\mathrm{J} / \mathrm{kg}), \rho_{\mathrm{w}}$ is the density of water $\left(\mathrm{kg} / \mathrm{m}^{3}\right)$ and $\Lambda$ is the instantaneous evaporative fraction. Calculation of AET differs for non-cloudy days and cloudy days in terms of the way $R_{\mathrm{n} 24}$ is computed.

\subsection{AET estimation for non-cloudy days}

SEBS can only be applied for a non-cloudy (free of cloud cover) satellite data and detail information on SEBS can be found in $\mathrm{Su}$ (2002). For a non-cloudy day, the instantaneous evaporative fraction $(\Lambda)$ can be calculated using latent heat flux and sensible heat flux:

$$
\Lambda=\frac{\Lambda_{r} \times \lambda E_{\text {wet }}}{R_{\mathrm{n}}-G_{0}}
$$

where $\lambda E_{\text {wet }}$ is the latent heat flux at wet limit $\left(\mathrm{W} / \mathrm{m}^{2}\right), \Lambda_{r}$ is the relative evapotranspiration, $R_{\mathrm{n}}$ is the net radiation $\left(\mathrm{W} / \mathrm{m}^{2}\right)$ and $G_{0}$ is the soil heat flux $\left(\mathrm{W} / \mathrm{m}^{2}\right) . R_{\mathrm{n}}$ is computed as the sum of incoming and outgoing short-wave and long-wave radiant fluxes which are calculated using MODIS data. Soil heat flux $\left(G_{0}\right)$ is calculated using $R_{\mathrm{n}}$ and fractional canopy coverage on ground. The fractional canopy cover is calculated using the normalized difference vegetation index (NDVI), which is calculated using MODIS data. The latent heat flux at wet limit (i.e. there is no limitation to water availability) is calculated as:

$$
\lambda E_{w e t}=R_{\mathrm{n}}-\left(G_{0}+H_{w e t}\right)
$$

where $H_{\text {wet }}$ is the sensible heat flux at wet limit $\left(\mathrm{W} / \mathrm{m}^{2}\right)$. The relative evapotranspiration $\left(\Lambda_{r}\right)$ is the ratio of sensible heat flux to its extreme limits (dry and wet), and calculated from:

$$
\Lambda_{r}=1-\frac{H-H_{\text {wet }}}{H_{d r y}-H_{\text {wet }}}
$$

where $H$ is the sensible heat flux $\left(\mathrm{W} / \mathrm{m}^{2}\right)$ and $H_{d r y}$ is sensible heat at the dry limit $\left(\mathrm{W} / \mathrm{m}^{2}\right) . H$ is computed using meteorological as well as MODIS data. The required meteorological data are wind speed, air temperature and sunshine hours. MODIS data were used to estimate the required surface roughness and surface temperature, which in turn were used to compute $H$. A self-calibration between dry (near zero evapotranspiration) and wet (reference evapotranspiration) conditions was used to estimate $H$. Estimation procedure for the $H, H_{d r y}$ and $H_{\text {wet }}$ is described in detail by $\mathrm{Su}(2002)$. The 24 hour averaged net radiation $\left(R_{\mathrm{n} 24}\right)$ is calculated as:

$$
R_{\mathrm{n} 24}=K_{d a y}+L_{d a y}
$$

where $K_{d a y}$ is the net short wave radiation $\left(\mathrm{W} / \mathrm{m}^{2}\right)$ for the day, and $L_{d a y}$ is the net long wave radiation $\left(\mathrm{W} / \mathrm{m}^{2}\right)$ for the day. The procedure for calculating $K_{d a y}$ and $L_{d a y}$ is described in detail by Su (2002). Calculated $\Lambda$ and $R_{\mathrm{n} 24}$ were used in (1) to estimate AET.

\subsection{AET estimation for cloudy days}

ET process is driven by available net solar energy. However, the cloud cover reduces the amount of energy reaching the land surface, thus reducing the ET. As Young \& Sabburg (2006) stated, cloud cover reduces solar radiation and temperature, while it increases humidity, irrespective of day or night. For cloudy days, the fraction of cloud cover 
Gamage et al., Estimation of Actual Evapotranspiration using remote sensing data

was computed using GOES infrared global geostationary composite images. This fraction was used to estimate shortwave radiation $(K \downarrow)$ (Allen et al., 1998). Then, $R_{\mathrm{n} 24}$ was calculated using (6) for cloudy days (De Bruin and Stricker, 2000):

$$
R_{\mathrm{n} 24}=\left(1-r_{0}\right) K \downarrow-110 * K \downarrow / K \downarrow_{\text {exo }}
$$

where $r_{0}$ is the broad band surface albedo estimated with MODIS data (Liang et al., 2002) and $K \downarrow_{\text {exo }}$ is the extraterrestrial radiation. This estimated net radiation $\left(R_{\mathrm{n} 24}\right)$ for a cloudy day was applied in to $(1)$ with the nearest non-cloudy day $\Lambda$ obtained by SEBS to estimate daily AET, assuming that the nearest non-cloudy day evaporative fraction is the same for the cloudy day.

\subsection{Accuracy assessment and error estimation}

The Penman-Monteith (PM) based AET is considered as real AET in this study as the PM method is widely accepted to produce the best estimates of AET with the absence of lysimeter data. The estimated AET using RS data (Sections 3.2 and 3.3) was compared against PM based AET (computed using reference crop evapotranspiration obtained from SILO dataset) using Root Mean Square Error (RMSE) and Nash-Sutcliffe efficiency $\left(E_{f}\right)$ (Pala, 2003; Nash and Sutcliffe, 1970).

\section{APPLICATION}

The methodology that was described in Section 3, was applied to estimate AET for the whole catchment using remote sensing data. The RS based estimates were then compared with PM based AET to assess the accuracy of RS estimation. The required PM based AET was calculated from PM based reference crop evapotranspiration downloaded from the SILO Data Drill using a crop coefficient $(0.9$ - based on existing vegetation of study area). The comparison was conducted for four locations uniformly covering the entire catchment: Barkley River point, Mt. Tamboritha, Licola and Mt Howitt.

\subsection{AET of non-cloudy days}

The estimated AET from both methods for non-cloudy
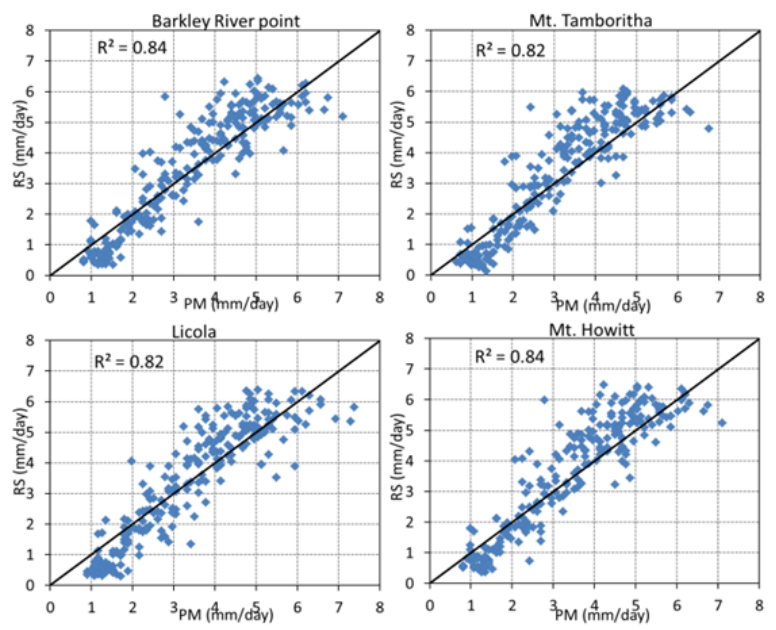

days are shown in Figure 2 for the selected four sites. based AET and PM based AET at each site is higher than 0.8, and do not show much variation despite different point meteorological data (i.e. air temperature) used in RS based AET estimation. Figure 2 shows that the RS based method over estimates AET compared to the PM based method, when AET is approximately over $3 \mathrm{~mm} / \mathrm{day}$. The AET above $3 \mathrm{~mm} /$ day mostly occurs during summer and autumn in the study area. During these seasons higher net radiation occurs due to low albedo (which is an indication of low outgoing radiation energy) in bare soil, matured grass and tree canopy, which may lead to higher AET in the RS based estimation.

\subsection{AET of cloudy days}

Figure 3 shows the RS based and PM based AET for cloudy days at the same four sites. This figure shows that most RS based AET values are underestimated compared to the PM based estimates. Many days are shown with zero or near-zero AET in the RS based estimation as a result of low net radiation available to AET, which is a result of total cloud or partial cloud cover in cloudy days. In addition, the RS based estimation does not consider
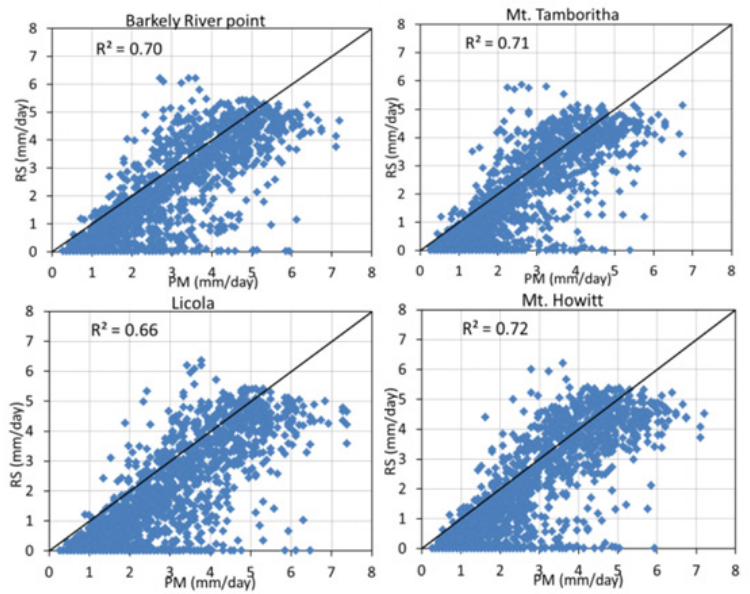

Figure 3 PM based AET and RS based AET for cloudv 
turbulence and soil heat flux, which produce high real and PM based AET values, and hence the RS based estimates can be underestimated, even if net radiation was estimated accurately using RS data. The low $\mathrm{R}^{2}$ on cloudy days compared to those of non-cloudy days could be due these reasons. Similar to the non-cloudy days, the variation of $\mathrm{R}^{2}$ among the sites are negligible.

\subsection{Accuracy assessment of both non-cloudy and cloudy days}

SEBS estimates AET by calculating net radiation and aerodynamic effect, which are affected by physical and biological factors in the environment. These two factors (i.e. physical and biological factors) should be well represented in the estimation process to have an accurate estimation of AET. However the link between these factors and AET is complex, which will lead to inevitable model errors. These factors are represented in the AET estimation process through many variables such as albedo, air temperature, wind speed, pressure deficit, emissivity, vegetation type and growth stage. Measuring and estimating some of these variables with RS data may have produced errors and these errors will propagate to AET estimation via SEBS. This may cause erroneous results in RS based AET estimates for both non-cloudy and cloudy days.

The net short wave radiation is the most significant component in estimating net radiation and it was calculated based on land surface albedo. Therefore albedo becomes a sensitive variable for RS based AET estimation, and the errors in albedo calculations could lead to errors in RS based AET estimation. Therefore for these reasons, an accuracy assessment and error estimation was conducted to investigate the accuracy of RS based AET estimates compared to PM based AET estimates. This was carried out separately for non-cloudy and cloudy days for all four sites, as shown in Table 1.

The calculated RMSE and $E_{f}$ show similar results

Table 1. RMSE and $E_{f}$ values for total period of study

\begin{tabular}{|l|c|c|c|c|}
\hline \multirow{2}{*}{} & \multicolumn{2}{|c|}{ Non-cloudy days } & \multicolumn{2}{c|}{ Cloudy days } \\
\cline { 2 - 5 } & RMSE & $E_{f}$ & RMSE & $E_{f}$ \\
\hline Barkley River point & 0.75 & 0.52 & 1.22 & 0.22 \\
\hline Mt. Tamboritha & 0.81 & 0.44 & 1.06 & 0.27 \\
\hline Licola & 0.79 & 0.49 & 1.37 & 0.11 \\
\hline Mt. Howitt & 0.79 & 0.49 & 1.15 & 0.26 \\
\hline
\end{tabular}

at all four sites, but differently for non-cloudy and cloudy days, and they were quite similar to the $\mathrm{R}^{2}$ values in both Figures 2 and 3. According to Barton \& Meyer (2008), PM underestimates ET during warm days with high radiation and more advective (turbulence) effect, and slightly overestimates during cool days with low radiation and less advective effect. This is consistent with Figure 2, that shows RS based AET slightly underestimates on such cool days (AET less than $2 \mathrm{~mm}$ /day) and overestimates during warm days (AET more than $2 \mathrm{~mm} /$ day). This implies that the RS based AET may be closer to real AET, especially on non-cloudy days.

\section{CONCLUSIONS}

Estimation of actual evapotranspiration (AET) and its spatial distribution are immensely important to understand the catchment hydrology. However, the physical and biological processes of AET make its quantification difficult and make it further difficult in most cases due to lack of required data. In the absence of such data, remote sensing data and globally available climate datasets were used in this study to estimate AET. These AET estimates were compared against Penman-Monteith (PM) based AET estimates. PM based potential evapotranspiration is widely used in Australia to estimate AET, as a surrogate for lysimeter measurements. This approach of comparing RS based estimates with those of PM may not be relevant to catchments where accurate PM based estimates are not available. The results show that the overall accuracy of estimation is stronger for non-cloudy days. AET estimates were underestimated on both partial and total cloudy days due to inadequate representation of RS data in quantifying the sensible heat flux. Total cloudy day AET estimates were largely underestimated compared to those of partially cloudy days. The AET values thus computed from RS data can be used to generate streamflow data through a catchment process model for catchments where meteorological data are not available. This will be studied in a future study together with how errors occur in ET computations using RS data will propagate into streamflow data generation. 
Gamage et al., Estimation of Actual Evapotranspiration using remote sensing data

\section{REFERENCES}

Allen, R. G., Pereira, L. A., Raes, D., and Smith, M. (1998). Crop evapotranspiration: guidelines for computing crop water requirements. . FAO Irrigation and Drainage Paper 56. Rome, Italy: FAO.

Barton, A. B., and Meyer, W. S. (2008). An Analysis of Method and Meteorological Measurement for Evapotranspiration Estimation Part 1: Results using weather data from Griffi th, NSW. CRC for Irrigation Futures Technical Report. CRC for Irrigation Futures

Bastiaanssen, W. G. M., Menenti, M., Feddes, R. A., and Holtslag, A. a. M. (1998). A remote sensing surface energy balance algorithm for land (SEBAL) 1. Formulation. Journal of Hydrology, 212-213, 198-212.

Biggs, T. W., Mishra, P. K., and Turral, H. (2008). Evapotranspiration and regional probabilities of soil moisture stress in rainfed crops, southern India. Agricultural and Forest Meteorology, 148, 1585-1597.

Chow, V. T., Maidment, D. R., and Mays, L. W. (1988). Applied Hydrology, USA, McGraw-Hill, Inc.

De Bruin, H. a. R., and Stricker, J. N. M. (2000). Evaporation of grass under nonrestricted soil moisture conditions. Hydrological Science Journal 45, 391- 406.

Dingman, S. L. (1994). Physical hydrology, Englewood Cliffs, NJ., Prentice-Hall, Inc.

Fitzmaurice, L., and Beswick, A. (2005). Sensitivity of the FAO56 crop reference evapotranspiration to different input data. Indooroopilly: Queensland Department of Natural Resources and Mines.

Glenn, E. P., Huete, A. R., Nagler, P. L., Hirschboeck, K. K., and Paul, B. (2007). Integrating remote sensing and ground methods to estimate evapotranspiration. Critical Reviews in Plant Sciences, 26, 139 - 168.

Justice, C. O., Townshend, J. R. G., Vermote, E. F., Masuoka, E., Wolfe, R. E., Saleous, N., Roy, D. P., and Morisette, J. T. (2002). An overview of MODIS Land data processing and product status. Remote Sensing of Environment, 83, 3-15.

Kite, G. W., and Pietroniro, A. (1996). Remote sensing applications in hydrological modelling. Hydrological Sciences Journal, 41.

Liang, S., Chad, J. S., Andrew, L. R., Hongliang, F., Mingzhen, C., Charles, L. W., Craig, S. T. D., and Raymond, H. J. (2002). Narrowband to broadband conversions of land surface albedo:II Validation. Remote Sensing of Environment 84, 25-41.

Monteith, J. L. (1965). Evaporation and environment. In: Fogg, G. (Ed.), The State and Movement of Water in Living Organisms. In: Proceedings of the XIXth Symposium on the Society of Experimental Biology, (1965). Cambridge University Press, Cambridge, UK, 205 - 234.

Nash, J. E., and Sutcliffe, J. V. (1970). River flow forecasting through conceptual models part I - A discussion of principles. Journal of Hydrology, 10, 282-290.

New, M., Lister, D., Hulme, M., and Makin, I. (2002). A high-resolution data set of surface climate over global land areas. Climate Research, 21, 1-25.

Pala, A. (2003). Runoff modelling of rural catchments in Turkey. Journal of Arid Environments, 54, 505-512.

Peel, I., Watson, F., Vertessy, R., Lau, A., Watson, I., Sutton, M., and Rhodes, B. (2000). Predicting the water yield impacts of forest disturbance in the Maroondah and Thomson catchments using the Macaque model. Technical report Cooperative Research Centre for Catchment Hydrology.

Penman, H. L. (1948). Natural evaporation from open water, bare soil, and grass. In: Proc. Roy. Soc. London, (1948). 120-146.

Priestley, C. H. B., and Taylor, R. J. (1972). On the assessment of surface heat flux and evaporation using large scale parameters. Monthly Weather Review, 100, 81-92.

$\mathrm{Su}$, Z. (2002). The Surface Energy Balance System (SEBS) for estimation of turbulent heat fluxes. Hydrology and Earth System Sciences, 6, 85-99.

Thenkabail, P. S., Gamage, M. S. D. N., and Smakhtin, V. U. (2004). The use Of remote sensing data for drought assessment and monitoring In South West Asia. IWMI Research Report, No 85. Colombo, Sri Lanka.: International Water Management Institute.

Thornthwaite, C. W. (1948). An approach toward a rational classification of climate. Geographical Review, 38, 5594.

Young, A. R., and Sabburg, J. (2006). Cloud effects on evaporation at a sub-tropical site. Australian Institute of Physics 17th National Congress. Brisbane. 